ORIGINAL ARTICLE

\title{
Proportion of Glaucoma among Voluntary People Coming for Glaucoma Screening Program at Jimma University Department of Ophthalmology, Jimma, Ethiopia
}

\author{
Kumale Tolesa Daba ${ }^{*}$, Girum W. Gessesse ${ }^{2}$, Sisay Bekele Sori ${ }^{1}$
}

\section{OPEN ACCESS}

Citation: Kumale Tolesa Daba, Girum W. Gessesse, Sisay Bekele Sori. Proportion of Glaucoma among Voluntary People Coming for Glaucoma Screening Program at Jimma University Department of Ophthalmology, Jimma, Ethiopia. Ethiop J Health Sci. 2020; 30(1):13.doi:http://dx.doi.org/10.4314/ejh s.v30 i1.3

Received: May 1, 2019

Accepted: August 26, 2019

Published: January 1,2020

Copyright: (C2020 Kumale Tolesa Daba, et al. This is an open access article distributed under the terms of the Creative Commons Attribution License, which permits unrestricted use, distribution, and reproduction in any medium, provided the original author and source are credited.

Funding: Nil

Competing Interests: The authors declare that this manuscript was approved by all authors in its form and that no competing interest exists.

Affiliation and Correspondence:

${ }^{1}$ Department of Ophthalmology, Jimma University

${ }^{2}$ Department of Ophthalmology Saint Paul's Hospital Millennium Medical College

*Email:kumegery@gmail.com

\section{ABSTRACT}

BACKGROUND: Glaucoma is the second leading cause of blindness worldwide. Glaucoma screening has been controversial, and much of the controversy has centered on the value of mass or community screening.

METHODS: The aim of this study was to determine the proportion of glaucoma among volunteer adults who were screened in Jimma University Department of Ophthalmology. A cross-sectional study was conducted among 459 volunteer residents of Jimma town and surrounding areas. The study subjects were aged 40 years and above, who came for community screening program after media announcement during the four consecutive weekends of November 2014. Comprehensive eye examination was done including best corrected visual acuity, intra-ocular pressure measurement, stereoscopic optic nerve evaluation, angle structure evaluation and visual field testing. Three diagnostic criteria for glaucoma were employed for all cases.

RESULTS: Of all adults who came for screening, 47(10.24\%) were diagnosed to have glaucoma, 59(12.85\%) were glaucoma suspects, and $8(1.74 \%)$ had ocular hypertension. The proportion of glaucoma increased with increasing age, $(P$ value $=0.001$ (99\%CI)). Primary open angle glaucoma was the most common form (42.55\%) of all new cases while 4.4\% of all screened adults were followed by normal tension glaucoma (29.79\%), pseudoexfoliative glaucoma (19.15\%), and primary angle closure glaucoma (6.38\%) Around 5.7\% of all glaucoma cases were found to be blind.

CONCLUSION: The proportion of glaucoma in this community screening program in Southwest Ethiopia was $10.24 \%$ with primary open angle glaucoma being the commonest subtype. Glaucoma community screening should be promoted for early diagnosis and intervention to prevent irreversible blindness.

KEYWORDS: Glaucoma, Jimma, community screening, blindness, Intra-ocular pressure 


\section{INTRODUCTION}

The World Health Organization (WHO) estimated the global population of people with high IOP $(>21$ $\mathrm{mm} \mathrm{Hg}$ ) at 104.5 million. The incidence of Primary Open Angle Glaucoma (POAG) was estimated at 2.4 million people per year. The different types of glaucoma are responsible for $15 \%$ of blindness, placing glaucoma as the second leading cause of blindness worldwide, following cataract $(1,2)$.

Screening for POAG has been controversial, and much of the controversy has centered on the value of mass or community screening (3-6). Mass or community screenings are typically performed on unselected populations such as community centers, shopping centers, churches, or on partially selected populations such as all volunteer employees working in a large corporate building (3).

Critical review of the literature by the United States Preventive Services Task Force (UPSTF) on the effectiveness of screening and treatment for early POAG found good evidence that early treatment of adults with increased IOP detected by screening reduces the number of persons who develop visual field defects. This in turn leads to early treatment of those with early, asymptomatic POAG which decreases the number of those whose visual field progressed (3).

There are few data regarding the community screening in Africa. Of those, a prevalence survey for POAG on residents of 30 years and above in the Akwapim-South district of Ghana (7); the prevalence study of Primary Angle Closure Glaucoma (PACG) and Open Angle Glaucoma in Mamre, Western Cape, South Africa (8) can be mentioned. According to a survey done in Ghana, a total of 158 cases of glaucoma were diagnosed. Out of these, $94.3 \%$ were of POAG while $5.7 \%$ were of the chronic angle closure type (7). As to the South Africa's survey, the prevalence of PACG and POAG were $2.3 \%$ and $1.5 \%$ respectively (8).

Todate, there is no targeted glaucoma screening program done in Ethiopia. The aim of this study was thus to determine the proportion of glaucoma among adults aged 40 years and above who presented for glaucoma screening program after media announcement in a tertiary eye care center in Southwest Ethiopia.

\section{MATERIALS AND METHODS}

This is a cross-sectional study conducted among volunteer residents of Jimma Town and surrounding areas aged 40 years and above who came to Jimma University Department of Ophthalmology on a community screening program conducted after media announcement in 4 consecutive weekends of November 2014. Announcement about the need for screening was broadcast by local radio station; messages using poster were also posted in the populated areas of the town. All people aged 40 years and above who came for screening were enrolled. There were 4 patients who were excluded from the study since they had been diagnosed to have glaucoma or ocular hypertension previously and lost from follow-up for various reasons; or were already on antiglaucoma treatment; or there was clinical evidence suggesting prior glaucoma surgery (laser or incisional).

Checklist was developed after reviewing literatures and was used for everyone who appeared for screening. This checklist included socio-demographic characteristics of the participants, medical and ophthalmic history, as well as findings of ophthalmologic assessment. Each person was interviewed by ophthalmic nurses, cataract surgery students and a senior resident in ophthalmology while the ophthalmic examination was performed by a senior resident and ophthalmologist or glaucoma specialist.

Evaluation included best corrected visual acuity using Snellen E- chart and slit-lamp biomicroscopy. Intraocular Pressure (IOP) was measured by i-care tonometer, which takes average of 6 measurements, and calibrated Goldman applanation tonometry. Goldman applanation tonometry was taken when inconsistent IOP was measured using i-care tonometer. The diagnosis of high IOP was confirmed after 3 different measurements were taken, or suggestive diurnal IOP in patients with Normotensive glaucoma. Central corneal thickness (CCT) was measured by a contact ultrasound pachymeter (Pachmate DGH55, DGH-KOI, Inc. Shermans Dale, PA, USA). An average of twenty-five consecutive measurements were recorded in each eye by the pachymeter machine, such that each recording had a standard deviation $<5 \mu \mathrm{m}$. Gonioscopy was done

DOI: http://dx.doi.org/10.4314/ejhs.v30i1.3 
using Zeiss 4-mirror lens. Dilated fundus examination was done in case of small pupil and hazy media due to anterior segment abnormalities like early cataract and corneal opacity. Interobserver variations on the assessment of Optic Nerve Head $(\mathrm{ONH})$ were managed by doing a pretest where each ophthalmologist had two observations using a 90-D lens and a slit lamp. Then, the assessments were compared, and a common consensus was attained after the Kappa statistic was calculated to be 0.54 , with the grading by the ophthalmologists rounded to the nearest 0.1 -0.2 CDR unit.

Visual Field (VF) testing was done using Humphrey Frequency Doubling Technology (FDT) using the N-30 program (Zeiss Humphrey Systems, Dublin, CA) for persons who had vertical cup-todisc ratio (CDR) 0.5 or more or those with IOP > $21 \mathrm{mmHg}$. When we had an abnormal value, we repeated the test 2 times. Tests that were nonspecific were evaluated again using Humphrey VF analyzer.

Data were checked daily for completeness, inconsistency and outliers by looking at their distribution. Data were cleared, cleaned and analyzed using SPSS for Windows version 16.0 software. $\mathrm{X}^{2}$ test was performed and P-value $<0.05$ was used to identify the association between variables such as age, sex, IOP, CCT, glaucoma subtypes and systemic illnesses.

Operational definitions: The definition of POAG for this survey depends on the grading of the optic disc by the ophthalmologist, the VF finding, the absence of an occludable angle as detailed below and the absence of a secondary cause for glaucoma with IOP $>21 \mathrm{mmHg}$. We took the worst eye for staging of the disease and comparison of variables, but if an eye had corneal opacity or other anterior segment pathologies, we took the other eye for staging. We used three levels of definition for POAG (9):

A. Definition 1- defined glaucoma only by the optic disc finding by the ophthalmologist. The following structural features, when present in at least one eye, defined a person as having open angle glaucoma (OAG): CDR 0.9 or higher; or CDR higher than 0.7 with one or more of the following additional features: an abnormal nerve fiber layer (NFL), at least one clock hour of complete rim loss (notch), or CDR asymmetry between eyes of 0.3 or more in the eyes that had less than a 0.2-unit difference in disc diameter.

B. Definition 2- included persons with the structural features described, and in addition, included those who had in at least one eye a definite, reliable VF abnormality that matched the optic nerve appearance (per the listed definitions) and had a CDR of 0.7 or more or a CDR asymmetry between fellow eyes of 0.2 or more (not explained by a disc diameter difference of 0.2 units).

C. A third level of diagnosis for POAG (definition 3) included those in definitions 1 and 2, but it also included those who had at least one or more of the following $\mathrm{ONH}$ features: an abnormal NFL, at least one clock hour of complete rim loss (notch), or with CDR of 0.5 or more and a definite, reliable field defect that matched the optic nerve appearance. Therefore, the optic disc and VF findings were used for diagnosis in every subject in which both are available.

The criteria for early glaucomatous VF defect on FDT were one or more of the following:

1. Mean deviation and pattern standard deviation greater than or equal to - $4 \mathrm{db}$;

2. The presence of five or more altered points with $\mathrm{p}<5 \%$ and/or two or more altered points with $\mathrm{p}<2 \%$ and/or at least one altered point with $\mathrm{p}<1 \%$ at any location.

Normal Tension Glaucoma (NTG) was diagnosed based on the above $\mathrm{ONH}$ and VF features with IOP $<22 \mathrm{mmHg}$ and diurnal IOP difference of $<4 \mathrm{mmHg}$ between the highest and lowest measurements. Diagnosis of Pseudoexfoliative Glaucoma (PXG) was based on the above $\mathrm{ONH}$ and/or VF features and the presence of characteristic exfoliated material on the pupil margin or anterior surface of the lens on biomicroscopy in addition to 1 or more of the following findings on gonioscopy: heavy angle pigmentation, Sampaolesi line or exfoliated material in the angle recess. 


\section{Stage of Glaucoma}

Normal test: A test with no abnormal points in the 5 areas that are more central and in the 2 nonperipheral nasal areas, and with no more than 1 abnormal point with a $\mathrm{P}<5 \%$ in the periphery

Early defect: One or more abnormal points in the central 5 areas and in the 2 non-peripheral nasal areas, and/or more than $1 \mathrm{P}<5 \%$ defect or at least $1 \mathrm{P}<2 \%$ defect in the periphery. A defect is considered to be early until it reaches the limits for a moderate defect.

Moderate defect: More than $2 \mathrm{P}<2 \%$ adjacent defects, and/or more than 4 non-adjacent $\mathrm{P}<$ $1 \%$ defects, or more than 6 non-adjacent $\mathrm{P}<5 \%$ defects with at least $2 \mathrm{P}<1 \%$ abnormal points, or more than 9 non-adjacent $\mathrm{P}<5 \%$ defects. A defect is considered to be moderate until it reaches the limits for a severe defect.

Severe defect: Those tests with more than 12 abnormal points with more than $6 \mathrm{P}<0.5 \%$ defects, and/or more than $9 \mathrm{P}<1 \%$ defects.

Ethical considerations: We obtained ethical clearance from Jimma University Department of Ophthalmology (JUDO) adhering to the tenets of the declaration of Helsinki. We obtained verbal informed consent from all subjects who participated in this study. We collected the data with no identification of individual name, and all information was kept confidential. All patients diagnosed as glaucoma received appropriate management and follow-up. The participants benefited from health education given on the awareness of glaucoma while being screened. The use of any animal or human data or tissue was not applicable in this study.

\section{RESULTS}

A total of 459 volunteer adults were examined during the screening period and the majorities $(68.9 \%)$ were male. All participants were 40 years and older with a mean age of $51(\mathrm{SD} \pm 9.66)$ years. Those in the age range 40-45(36.4\%) years accounted for the greater proportion followed by those in the age range 46-50(22.2\%) years and 51$55(14.2 \%)$ years. Participants were civil servants $(36.2 \%)$, and $72(15.7 \%)$ were housewives, $59(12.9 \%)$ were farmers while 54(11.8\%) were merchants. Around one third of the participants had primary school education whereas $110(24 \%)$ adults had college/university education, and 84 (18.3\%) were illiterate. Three fourth of the participants came from Jimma while and the rest came from rural areas of the surrounding (Table 1).

Of the population screened, 59(12.9\%) were glaucoma suspects, and 47(10.2\%) were newly diagnosed glaucoma cases. All the 47 newly diagnosed glaucoma patients were under the definition 3 of the diagnostic criteria. Of these 20 were also under definition 1, and 2 (15(3.3\%) were diagnosed using definition 1 per se. Five (1.1\%) were diagnosed using the additional criteria stated under definition 2 . Twenty seven $(5.9 \%)$ were diagnosed using the additional criteria stated under definition 3). Eight (1.7\%) patients were found to have ocular hypertension. Among the newly diagnosed glaucoma patients, 20(42.6\%) had POAG, 14(29.8\%) had NTG, 9(19.2\%) had PXG, $3(6.4 \%)$ PACG and one (2.1\%) had aphakic glaucoma (Figure 1). The major type of glaucoma in this population was OAG. The ratio of POAG to PACG was calculated to be $7: 1$.

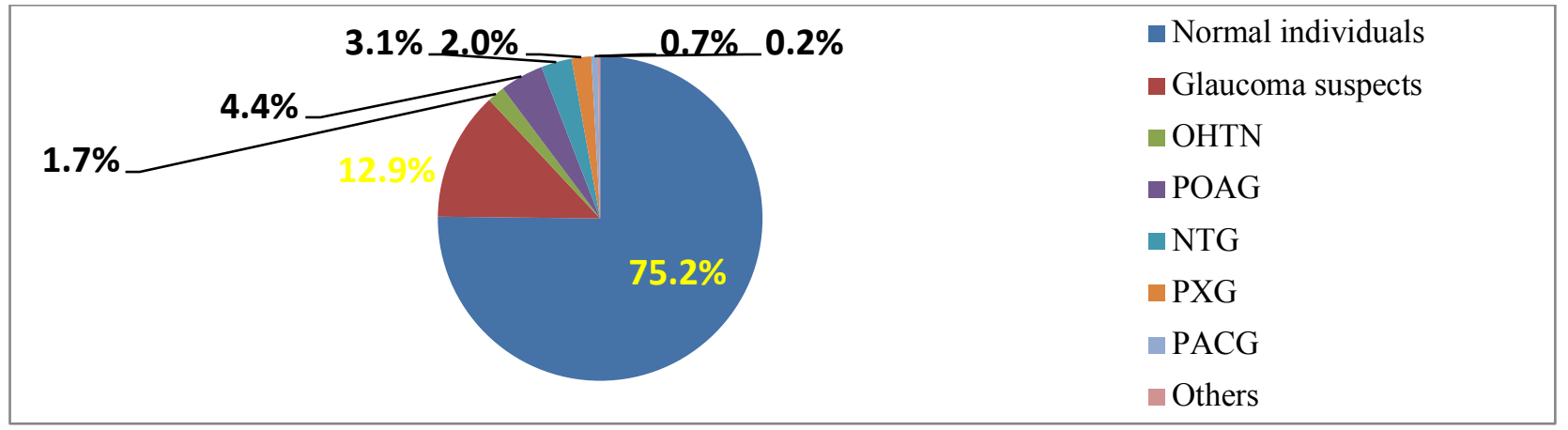

Figure 1: Final diagnosis of individuals screened for glaucoma in Jimma, Southwest Ethiopia

DOI: http://dx.doi.org/10.4314/ejhs.v30i1.3 
Table 1: Demographic characteristics of individuals screened for glaucoma in Jimma south west Ethiopia

\begin{tabular}{|c|c|c|c|}
\hline \multirow[t]{2}{*}{$\begin{array}{l}\text { Demographic } \\
\text { characterstics }\end{array}$} & \multicolumn{2}{|l|}{ Gender } & \multirow[t]{2}{*}{$P$ - value } \\
\hline & Male & Female & \\
\hline \multicolumn{4}{|l|}{ Age in years } \\
\hline $40-45$ & $105(33.2 \%)$ & $62(43.4 \%)$ & $\mathrm{P}$-value $=0.039$ \\
\hline $46-50$ & $67(21.2 \%)$ & $35(24.5 \%)$ & $99 \% \mathrm{CI}$ \\
\hline $51-55$ & $44(13.9 \%)$ & $21(14.7 \%)$ & \\
\hline $56-60$ & $50(15.8 \%)$ & $9(6.3 \%)$ & \\
\hline $61-65$ & $24(7.6 \%)$ & $8(5.6 \%)$ & \\
\hline$>66$ & $26(8.2 \%)$ & $8(5.6 \%)$ & \\
\hline \multicolumn{4}{|l|}{ Ethnicity } \\
\hline Oromo & $180(57.0 \%)$ & $64(44.8 \%)$ & P-value $<0.001$ \\
\hline Amhara & $43(13.6 \%)$ & $39(27.3 \%)$ & $99 \% \mathrm{CI}$ \\
\hline Dawro & $30(9.5 \%)$ & $13(9.1 \%)$ & \\
\hline Kefa & $17(5.4 \%)$ & $8(5.6 \%)$ & \\
\hline Tigre & $6(1.9 \%)$ & $5(3.5 \%)$ & \\
\hline Gurage & $22(7.0 \%)$ & $10(7.0 \%)$ & \\
\hline Others & $18(5.7 \%)$ & $4(2.8 \%)$ & \\
\hline \multicolumn{4}{|l|}{ Occupation } \\
\hline Civil servant & $120(38.0 \%)$ & $46(32.2 \%)$ & P-value $<0.001$ \\
\hline Merchant & $42(13.3 \%)$ & $12(8.4 \%)$ & $99 \% \mathrm{CI}$ \\
\hline Farmer & $57(18.0 \%)$ & $5(3.5 \%)$ & \\
\hline House wife & $0(0 \%)$ & $69(48.3 \%)$ & \\
\hline Self employed & $37(11.7 \%)$ & $4(2.8 \%)$ & \\
\hline NGO & $8(2.5 \%)$ & $1(0.7 \%)$ & \\
\hline Retired & $27(8.54 \%)$ & $5(3.5 \%)$ & \\
\hline Others & $25(7.91 \%)$ & $1(0.7 \%)$ & \\
\hline \multicolumn{4}{|l|}{ Literacy status } \\
\hline Illiterate & $41(13.0 \%)$ & $43(30.1 \%)$ & P-value $<0.001$ \\
\hline Read and write & $1(0.3 \%)$ & $1(0.7 \%)$ & $99 \% \mathrm{CI}$ \\
\hline Primary school & $118(37.3 \%)$ & $48(33.6 \%)$ & \\
\hline Secondary school & $83(26.3 \%)$ & $21(14.7 \%)$ & \\
\hline Collage and above & $80(25.3 \%)$ & $30(21.0 \%)$ & \\
\hline \multicolumn{4}{|l|}{ Residence } \\
\hline Urban & $224(70.9 \%)$ & $118(82.5 \%)$ & P-value $<0.001$ \\
\hline Rural & $92(29.1 \%)$ & $25(17.5 \%)$ & $99 \% \mathrm{CI}$ \\
\hline \multicolumn{2}{|c|}{$\begin{array}{l}\text { This study showed that the proportion of glaucoma } \\
\text { increases with increasing age; } 7.1 \% \text { (19) of patients } \\
\text { aged } 40-50 \text { years and } 19.7 \% \text { of patients aged above } \\
60 \text { years. This was statistically significant (P } \\
\text { value }=0.001(99 \% \mathrm{CI}) \text { ): the mean age of normal } \\
\text { individuals, OHT, glaucoma suspects and } \\
\text { glaucoma patients was } 50.2 \text { years }(\mathrm{SD}= \pm 9.58) \text {, } \\
49.6 \text { years }(\mathrm{SD}=\mathrm{SD}= \pm 9.03) \text { and } 52 \text { years } \\
(\mathrm{SD}= \pm 9.24) \text { and } 55.3 \text { years (SD }= \pm 9.84)\end{array}$} & \multicolumn{2}{|c|}{$\begin{array}{l}\text { respectively. This was statistically significant }(\mathrm{p}- \\
\text { value }=0.001,99 \% \mathrm{CI}) \text {. } \\
\text { Patients with PXG were older than the other } \\
\text { types of glaucoma with the mean age of patients } \\
\text { with POAG, NTG, PACG and PXG being } 54.9 \\
\text { years }(\mathrm{SD}= \pm 11.46), 53.1 \text { years }(\mathrm{SD}=+8.4), 51 \text { years } \\
(\mathrm{SD}= \pm 6.56) \text { and } 61.8 \text { years (SD=+7.22) } \\
\text { respectively. This difference was statistically } \\
\text { significant (P-value }=0.003,95 \% \mathrm{CI}) \text {. }\end{array}$} \\
\hline
\end{tabular}


The mean IOP of the glaucoma patients was $21.6 \mathrm{~mm} \mathrm{Hg}(\mathrm{SD}= \pm 7.116)$ on the right eye and 22 $\mathrm{mm} \mathrm{Hg}(\mathrm{SD}= \pm 6.7 \overline{8} 5)$ on the left eye, ranging from $14-39 \mathrm{~mm} \mathrm{Hg}$. Glaucoma suspects had mean IOP of $15.6 \mathrm{~mm} \mathrm{Hg}(\mathrm{SD}= \pm 4.256)$ and $14.9 \mathrm{~mm} \mathrm{Hg}$ $(\mathrm{SD}= \pm 3.671)$. Normal participants had $13.7 \mathrm{~mm}$ $\mathrm{Hg}(\mathrm{SD}= \pm 2.982)$ and $14.2 \mathrm{~mm} \mathrm{Hg}(\mathrm{SD}= \pm 2.854)$ on the right eye and left eye respectively. Higher
IOP was associated with the presence of glaucoma (P- value $<0.001,99 \% \mathrm{CI})$. ANOVA analysis of the difference of the mean IOP between the glaucoma types with Post Hoc test, using Tukey HSD, showed that PXG patients had statistically significant higher mean IOP than POAG and NTG patients (P-value $<0.001,95 \% \mathrm{CI}, \mathrm{SD}=11.429$ ) (Figure 2).

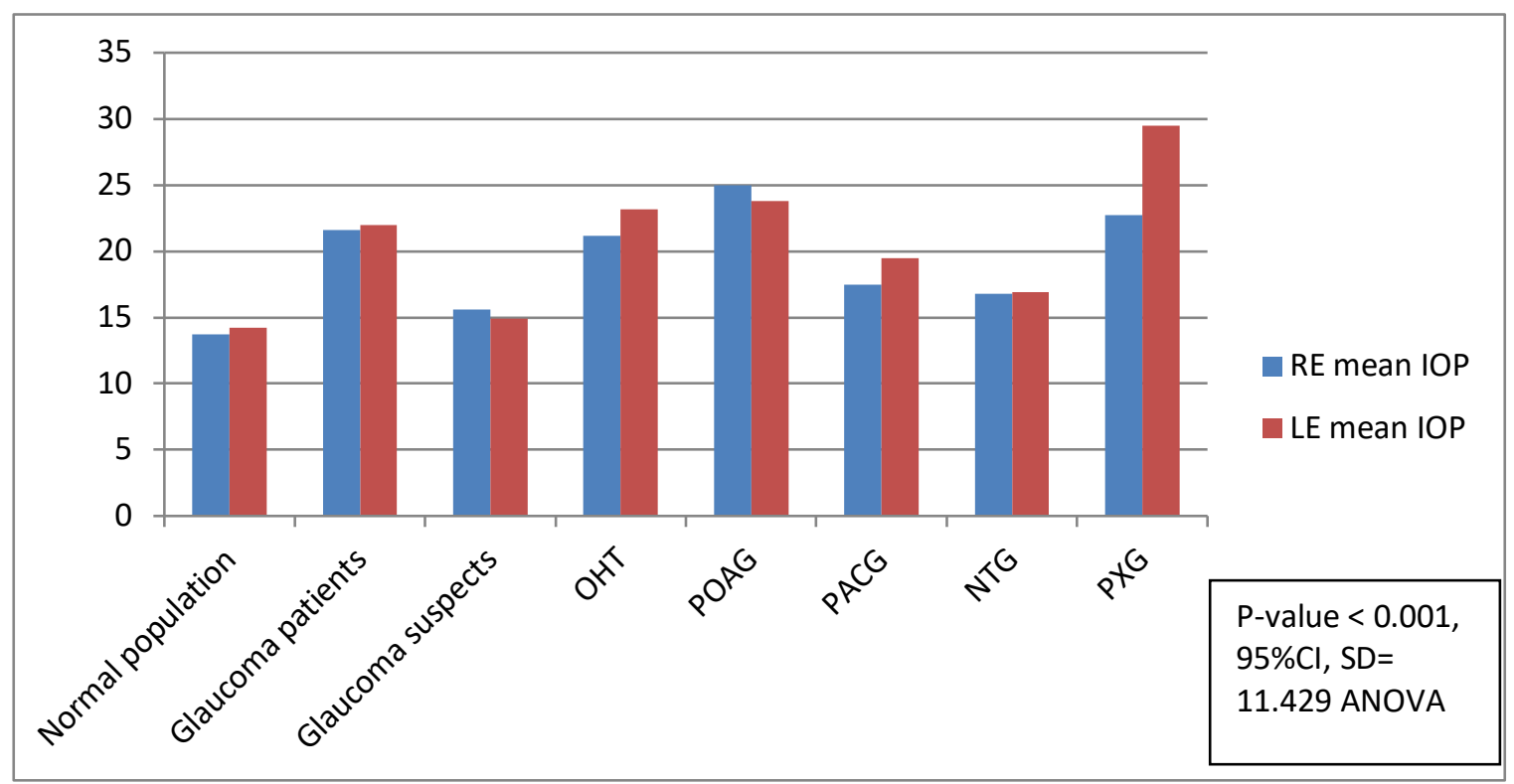

Figure 2: Mean IOP of normal population and individuals with different glaucoma subtypes in Jimma, south west Ethiopia

The study participants generally had a thinner CCT (mean $\mathrm{CCT}=532.9, \mathrm{SD}=42.15$ ). Glaucoma patients and suspects had non-significant thinner mean CCT than normal individuals. Patients with NTG had statistically significant thinner cornea than other types of glaucoma patients, (mean CCT $=505.6$,
$\mathrm{SD}=+23.34(\mathrm{P}$-value $=0.002,99 \% \mathrm{CI})$ (Figure 3). Patients with PXG had statistically significant difference in the measurement of CCT between the right and left eyes (mean $\mathrm{CCT}=544.1, \mathrm{SD}= \pm 37.73$ on the right eye and mean $\mathrm{CCT}=567.1, \mathrm{SD}= \pm 61.32$ on the left eye) (P-value $<0.001,99 \% \mathrm{CI})$.

Table 2: Comparison of type of glaucoma with stage of glaucoma in individuals screened for glaucoma in Jimma, Southwest Ethiopia

\begin{tabular}{lllll}
\hline \multirow{2}{*}{$\begin{array}{l}\text { Type } \\
\text { glaucoma }\end{array}$} & of & \multicolumn{4}{c}{ Stage of glaucoma } \\
\cline { 2 - 5 } & $\begin{array}{c}\text { Early } \\
\text { Number }(\%)\end{array}$ & $\begin{array}{c}\text { Moderate } \\
\text { Number }(\%)\end{array}$ & $\begin{array}{c}\text { Advanced } \\
\text { Number }(\%)\end{array}$ & \\
\hline POAG & $8(40.0)$ & $4(20.0)$ & $8(40.0)$ & P-value $<0.001$ \\
PXG & $3(33.3)$ & $3(33.3)$ & $3(33.3)$ & CI $99 \%=5.920$ \\
NTG & $11(78.6)$ & $3(21.4)$ & $0(0.0)$ & \\
PACG & $2(66.7)$ & $1(33.3)$ & $0(0.0)$ & \\
\hline
\end{tabular}

DOI: http://dx.doi.org/10.4314/ejhs.v30i1.3 


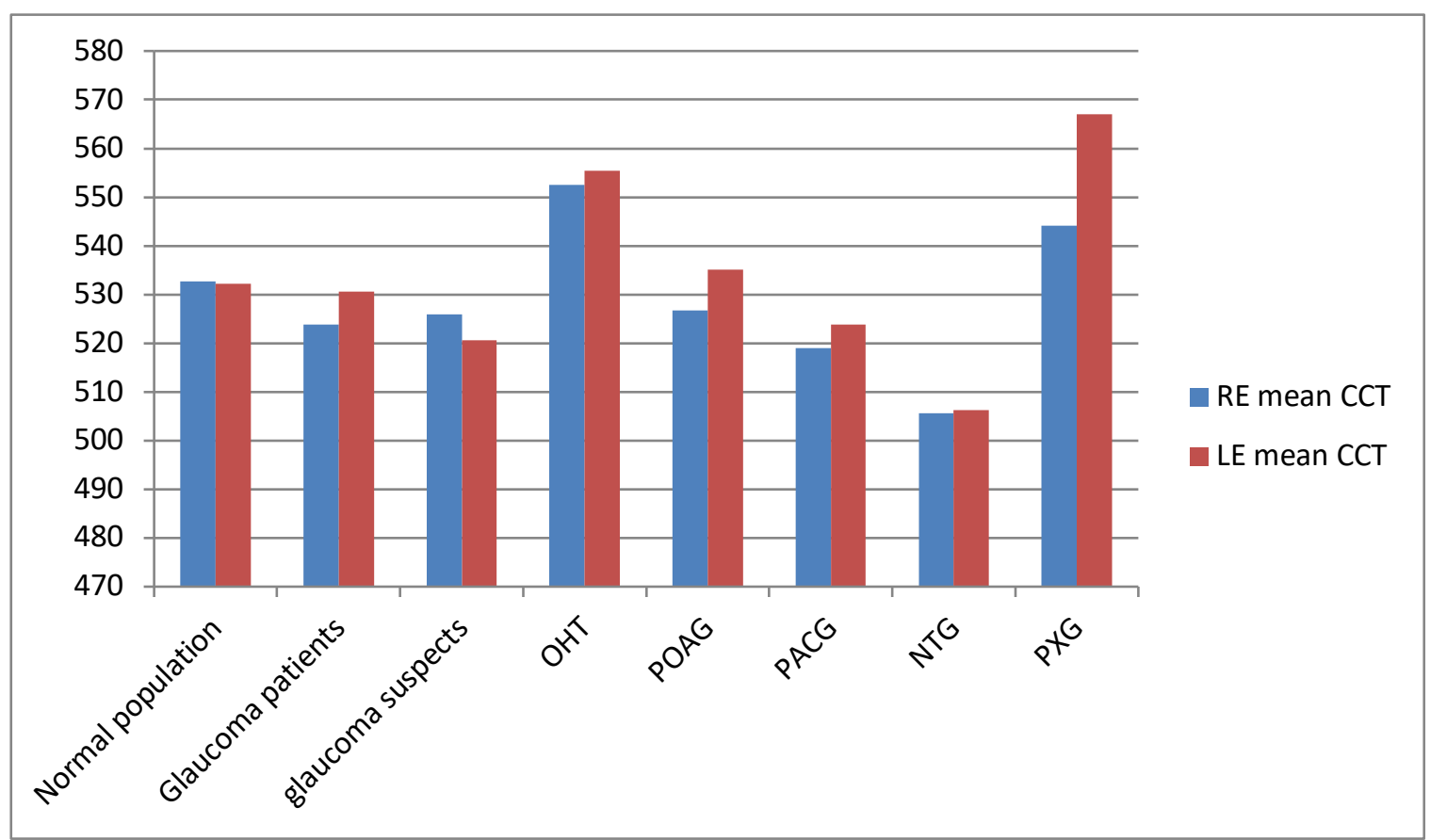

Figure 3: Mean CCT of normal population and individuals with different glaucoma subtypes in Jimma, Southwest Ethiopia

Of all glaucoma patients, 11(23.4\%) had moderate and advanced stage disc damage each, and $25(53.2 \%)$ of them had early stage in the worse eye. Of those cases who were diagnosed to have POAG, $8(40 \%)$ had advanced glaucomatous disc damage, whereas $3(33.3 \%)$ of PXG patients had advanced disc damage in the worse eye. From NTG cases, 11(78.6\%) had early disc damage in the worse eye. This was statistically significant (Pvalue $<0.001,99 \% \mathrm{CI}$ ) (Table 2 ).

Sequencing of products $(n=4)$ identified the organisms as Nocardia cyriacigeorgica $(\mathrm{n}=2), N$. farcinica $(\mathrm{n}=1)$ and Streptomyces albus $(\mathrm{n}=1)$. Among PCR positive patients, 4 were suffering from chronic broncho-pneumonia while one patient had co-infection of Klebsiella pneumoniae and Nocardia cyriacigeorgica. The results of sequencing confirmed the accuracy of PCR assay (GeneBank accession numbers: MK968270, MK968271, MK968277, MN043685).

Characteristics of study population and multiplex PCR sensitivity assessment: From four PCR positive patients, 2 were positive in direct smear (partially acid-fast and Gram staining) and took co-trimoxazole before specimen collection. This may be the reason for negative result of culture in these patients. Three other patients did not use antibiotics prior to the specimen collection. All 4 patients were suffering from lung cavitation or lung abscess. One patient had disseminated nocardiosis, which was is caused by Nocardia cyriacigeorgica. This organism was isolated from both brain abscess and BAL specimens.

\section{DISCUSSION}

Screening, which has higher case detection yield, is one of the tools to assess the prevalence of a disease in the community. Our study is the first of its type to assess the outcome of glaucoma detection among our population.

In this volunteer study, we found the proportion of glaucoma to be $10.2 \%$. This is almost comparable to the prevalence of the disease in the Ghanaian population (8.5\%) (7) and in St. Lucia, West Indies, (8.8\%) (10). But it is higher than large scale studies done in sub-Saharan Africa (4\%), Nigeria $(5.02 \%)$ and rural central Tanzania $(4.16 \%)(11,12,13)$. Half $(5.9 \%)$ of the newly diagnosed cases were diagnosed using both CDR

DOI: http://dx.doi.org/10.4314/ejhs.v30i1.3 
and VF examination (definition 3); similar to the population surveys in Kongwa (4.5\%), Tanzania (5.3\%) and Rural East Africa (3.1\%), which used three diagnostic criteria based on the optic disc and VF definitions $(11,13)$. POAG was the most common form of glaucoma in our population sample. Various studies have indicated that POAG is the commonest type of glaucoma among African population and this proportion increases with age $(1,2,8,11-13,16)$. PACG, PXG and NTG accounted for $6.4 \%, 19.2 \%$ and $29.8 \%$ of all glaucoma cases, respectively. This is comparable with a prevalence survey carried out in the Akwapim-South district of Ghana (PACG (5.7\%), and NTG(20.9\%))(7). A review of epidemiologic surveys of different types of glaucoma in SubSaharan Africa showed similar results (16\% PXG in Temba and 21.6\% PXG in Hlabisa in South Africa) (11). A previous clinic based study done in our setting in 2013 also found PXG to be the most common type (35.2\%) followed by POAG (32.8\%) and PACG (18.5\%) (14). The ratio of POAG to PACG was calculated to be 7:1. This result is similar to the glaucoma prevalence study done in remote rural Central India (ratio 8:1) (15).

We found that the proportion of glaucoma in our volunteer study increased with advancing age. This is comparable with the study in Western Cape, South Africa, and a review risk of factors in individuals of African descent $(8,16)$. The proportion of POAG in our volunteer study similarly increased with age. This is comparable to a population-based cross-sectional study done in Tema, Ghana $3.7 \%$ among those aged 40 to 49 years to $14.6 \%$ among those 80 years and older) (17). However, POAG occurred in the younger age group as compared to PXG where the mean age of patients with POAG was 54.9 years $(\mathrm{SD}=+11.46)$, and the mean age of PXG patients was 61.8 years $(\mathrm{SD}=+7.22))$. This finding supports the existing evidences that PXG is considered as a disease of the elderly (2) and the finding of the clinic based study done in JUDO (18).

Higher IOP was found to be significantly associated with the presence of glaucoma. This finding is expected, as IOP is the major risk factor for the development of glaucoma; different epidemiologic studies have shown similar results $(1,2,16)$. There was also statistically significantly higher mean IOP in PXG patients than other types. Previous studies revealed similar findings $(1,19,20)$.

The study participants generally had a thinner CCT. This is comparable to a multi-center cross-sectional study done on Ethiopian glaucoma patients (mean CCT: $508.07(\mathrm{SD}= \pm 33.26) \mu \mathrm{m}$ ) (21). A cross-sectional study in Ethiopians (mean CCT $518.68 \mu \mathrm{m}(\mathrm{SD}= \pm 32.92))(22)$, and clinic based study done recently in JUDO (mean CCT: $518.64 \mu \mathrm{m}(\mathrm{SD}=+40.81))(17)$.

We found that patients with NTG had significantly thinner cornea than other subtypes. This finding is similar to a case control study done in Switzerland (CCT in the group with NTG (521 +/-31 microns) was significantly lower than POAG group $(\mathrm{P}<0.001))(23)$.

In this volunteer study population, the proportion of glaucoma among adults who came to Jimma University Department of Ophthalmology for screening was $10.2 \%$, which increased with age. Screening for glaucoma provides useful information regarding burden of the disease. Glaucoma community screening and community awareness program should be advocated since it is very important for early diagnosis and management before it gets too late to save patients vision. This study is the first of its kind in Ethiopia using standard techniques of $\mathrm{ONH}$ evaluation and VF. Hence, it may serve as a baseline reference for further studies.

\section{AKNOWLEDGMENTS}

We would like to thank nurses at Jimma University Department of Ophthalmology, especially $\mathrm{Mr}$ Abdeta Bayisa, for their cooperation and hard work in the screening. We would like to thank Jimma University Specialized Hospital for the logistic and security support in conducting this screening program. We also would like to thank Professor Karim Damji for supporting this project. 


\section{REFERENCES}

1. American Academy of Ophthalmology. Basic and Clinical Science Course; Glaucoma: Section- 10. CA: San Francisco: American Academy of Ophthalmology, 2011.

2. Allingham RR. Shield's Text book of glaucoma: $\sigma^{\text {th }} \quad$ edition. Philadelphia: Wolters Kluwer/Lippincott Williams \& Wilkins, 2011.

3. Leah L, Bernard S. Glaucoma screening in the health care setting. Surv Ophthalmol. 1983;28(3):164-174.

4. Pollack IP. Glaucoma screening. Indian $J$ Ophthalmol. 1966; 14:1-5.

5. Thylefors B, Negler AD. The global impact of glaucoma. bulletin of the World Health Organization. 1994; 72 (3): 323-326.

6. Robert NW, Paul RH, Fotis T. World Glaucoma Association, Glaucoma screening, consensus series 5. Kugler Publications.2008:978-906299-218-8.

7. C T Ntim-Amponsah, W M K Amoaku, $\mathrm{S}$ Ofosu-Amaah et al. Prevalence of glaucoma in an African population. Eye. 2004; 18:491497.

8. John F, Andre M, Andrew I et al. The Prevalence of Primary Angle Closure Glaucoma and Open Angle Glaucoma in Mamre, Western Cape, South Africa. Arch Ophthalmol. 1993;111(9):1263-1269.

9. Foster PJ, Buhrmann R, Quigley HA, Johnson GJ. The definition and classification of glaucoma in prevalence surveys. $\mathrm{Br} J$ Ophthalmol. 2002; 86:238-242.

10. Mason RP, Kosoko O, Wilson MR, et al. National survey of the prevalence and risk factors of glaucoma in St Lucia, West Indies: Part I. Prevalence findings. Ophthalmology. 1989; 96:1363-8.

11. Fatima K, Mohammed MA, Andrew B, Clare E Gilbert F, Hannah F. Epidemiology of Glaucoma in Sub- Saharan Africa: Prevalence Incidence and Risk Factors. Middle East Afr J Ophthalmol. 2013; 20(2): 111-125.

12. Fatima K, Gabriel E, Mansur R, Paul S, Richard W, Winifred N, Gudlavalleti V. S. Murthy, Clare E. Gilbert and On behalf of the Nigeria National Blindness and Visual Impairment
Study Group. A Population-based survey of the prevalence and types of glaucoma in Nigeria: results from the Nigeria National Blindness and Visual Impairment Survey. BMC Ophthalmology (2015) 15:176

13. Ralf R. Buhrmann, Harry A. Quigley, Yolanda Barron, Sheila K. West, Matthew S. Oliva, and Boliface B. O. Mmbaga. Prevalence of Glaucoma in a Rural East African Population. Invest Ophthalmol Vis Sci.2000; 41:40 - 48

14. Addis T, Berhan S, Amare D. Glaucoma subtypes in Ethiopian clinic patients. J Glaucoma. 2013; 22 (2): 110-6.

15. Vinay N, Jost BJ, Songhomitra PJ. Prevalence and Associated Factors of Glaucoma in Rural Central India: The Central India Eye and Medical Study. PLoS One. 2013; 8 (9): e76434.

16. R Salowe, J Salinas, N H Farbman, A Mohammed, J Z Warren, A Rhodes, A Brucker, M Regina, E Miller-Ellis, P S Sankar, A Lehman and J M Brien. Primary Open-Angle Glaucoma in Individuals of African Descent: A Review of Risk Factors. J Clin Exp Ophthalmol 2015, 6:4

17. Donald LB, Keith B, James MT. Prevalence of Glaucoma in an Urban West African Population. JAMA Ophthalmol. 2013; 131(5): 651-658.

18. Kumale T, Girum WG. Central corneal thickness in newly diagnosed glaucoma patients in South West Ethiopia: a cross-sectional study. BMC Ophthalmol. 2016 31;16(1):152.

19. Mitchell P, Wang JJ, Hourihan F. The relationship between glaucoma and pseudoexfoliation: The Blue Mountains Eye Study. Arch Ophthalmol. 1999 ;117(10):131924.

20. Hiller R, Sperduto RD. Pseudoexfoliation, intraocular pressure, and senile lens changes in a population-based survey. Arch Ophthalmol. 1982;100(7):1080-2.

21. Yeshigeta Gelaw. The impact of central corneal thickness on intraocular pressure among Ethiopian glaucoma patients: a cross-sectional study. BMC Ophthalmology. 2012; 10.1186/1471-2415-12-58.

22. Yeshigeta G, Kollmann M , Njuguna_MI, Dunera RI. The influence of central corneal 
thickness on intraocular pressure measured by Goldmann applanation tonometry among selected Ethiopian communities. J glaucoma. 02/2010; 19(8):514-8.

23. Copt RP, Thomas R, Mermoud A. Corneal thickness in ocular hypertension, primary openangle glaucoma, and normal tension glaucoma. Arch Ophthalmol. 1999 Jan; 117(1):14-6. 